\title{
REYES DEL SOL Y SEÑORES DE LA LUNA. INKAS E YCHSMAS EN PACHACÁMAC
}

\author{
KINGS OF THE SUN AND LORDS OF THE MOON. \\ INKAS AND YCHSMAS AT PACHACÁMAC
}

\author{
Peter Eeckhout*
}

\begin{abstract}
Los Inkas en la cima de su potencia dominaban un imperio que integraba cerca de 100 etnias diferentes. Las crónicas nos enseñan que la estrategia de conquista se adaptaba según los casos y que los Inkas usaban tanto de la fuerza militar como de la negociación diplomática o de la alianza provisional. Varios autores han mostrado que la organización y la administración de los territorios y pueblos conquistados dependían de su propio grado de organización y administración antes de la conquista, así como del interés económico (u otro) a ojos de los Inkas. Para apreciar la índole de la inversión de los Inkas en las diferentes partes de su imperio, es importante conocer esas regiones antes de su integración. ¿Cómo se pueden percibir los cambios y manipulación de la identidad a través de las fuentes arqueológicas y etnohistóricas? ¿Qué nos dicen esos cambios respecto al proceso de integración imperial? Propongo debatir estas cuestiones en base a los datos disponibles a propósito de Pachacamac y de las investigaciones llevadas a cabo bajo mi dirección en este sitio y su comarca desde hace casi diez años.
\end{abstract}

Palabras claves: Inka, Pachacámac, identidad, religión, imperio.

At the climax of their power the Inkas dominated an empire that included some 100 different ethnic groups. Chronicles indicate that strategies of conquest, adapted to specific circumstances, included military force, as well as diplomacy and provisionary alliance. Various authors have demonstrated that the organization and administration of conquered peoples and territories depended on preconquest organizational complexity as well as perceived economic value. To appreciate the nature of Inka investment in different parts of their empire, it is important to understand preconquest conditions. How can one perceive changes and manipulations of the identity through archaeological and ethnohistorical records? What do these changes tell us about the process of imperial integration? I consider these issues for Pachacamac, including my own investigations at this site and its vicinity during the last 10 years.

Key words: Inka, Pachacamac, identity, religion, empire.

Según Rowe (1946:185-92), los Inkas en la cima de su potencia dominaban un imperio que constaba de cerca de 90 etnias diferentes. Las crónicas nos enseñan que la estrategia de conquista se adaptaba según los casos y que los Inkas usaban tanto de la fuerza militar como de la negociación diplomática o de la alianza provisional. Schreiber (1992:41-70) y otros autores (ver d'Altroy 1992:145-6; Hyslop 1990:268-9; Malpass 1994; Spalding 1984:90-4; Von Hagen y Morris 1998:190-6) han mostrado que la organización y la administración de los territorios y pueblos conquistados dependían de su propio grado de organización y administración antes de la conquista, así como del interés económico o de otro tipo que tuvieran a ojos de los nuevos señores. En consecuencia, si bien bastaba modificar la cumbre de las estructuras jerárquicas locales en zonas políticamente bien organizadas, como el ex reyno de Chi- mor, y someterlas bajo la dirección de algún alto funcionario del Imperio asistido de la fuerza de disuasión apropiada, a veces fue necesario, en otras regiones, crear estos organigramas a partir de grupúsculos antes mayormente independientes unos de otros -como en Huánuco Pampa (Morris y Thompson 1985), por ejemplo. Dichas estrategias tienen una incidencia directa y algo paradójica en el registro arqueológico, particularmente del punto de vista de la arquitectura. En efecto, donde existía una organización preinca suficientemente elaborada, los conquistadores no tuvieron que invertir mucho en términos de estructuras de élite, edificios administrativos, instalaciones para almacenamiento del tributo, etc. A la inversa, la gestión de territorios, recursos y etnias políticamente poco desarolladas necesitó la colocación de una infraestructura a veces considerable.

\footnotetext{
* Université Libre de Bruxelles, Faculté de Philosophie et Lettres (CP 175), Av. F. Roosevelt 50, B-1050 Bruxelles, Belgica. peeckhou@ulb.ac.be
} 
Si uno quiere, pues, apreciar la índole de la inversión de los Inkas en las diferentes partes de su imperio, es importante conocer mejor esas regiones antes de su integración (Matos Mendieta 1997:397). En el caso de los Ychsmas de Pachacámac, esto nos permite también apreciar el aporte de cada una de las partes en el desarrollo del sitio así como distinguir lo local de lo importado, y la manera con la cual las importaciones e imposiciones de todas clases han tomado en cuenta la especificidad autóctona.

¿Cómo se pueden percibir los cambios y manipulación de identidad a través de las fuentes arqueológicas y etnohistóricas? ¿Qué nos dicen esos cambios respecto al proceso de integración imperial? Propongo debatir esos cuestionamientos en base a los datos disponibles a propósito de Pachacámac y de las investigaciones llevadas bajo mi dirección en este sitio y su comarca desde casi diez años (Eeckhout 1999a, 2003).

\section{La Conquista Inka: Ychsma se vuelve Pachacámac}

Cerca de 1470 d.C. Topa Yupanqui y sus tropas entran en Pachacámac y toman la ciudad del Oráculo (Brundage 1963:317). Volveré sobre las condiciones de esta conquista, que tuvo un impacto profundo en el diseño del sitio: se construyeron numerosas estructuras nuevas, mientras otras se reutilizaron y se transformaron para conformarse a los requisitos de los nuevos señores. El establecimiento logra una importancia mucho más allá de su marco regional tradicional, pues el culto del Oráculo y el peregrinaje asociado se organizaron a nivel imperial. Toda la comarca fue transformada y los curacazgos ancestrales de los valles del Lurín y Rímac se incluyeron en el sistema político y administrativo inka: tres hunus de 10.000 tributarios (Cobo 1956, II:301-2). Los Inkas cambiaron hasta el nombre del sitio, que hasta entonces se llamaba Ychsma (Santillán 1879:32-33).

Entre las nuevas construcciones hay tres estructuras que atestiguan el alto estatus del lugar a ojos de los Inkas: un Templo del Sol, un ushnu y un Acllahuasi.

El Templo del Sol se ubica en la parte más sureña del Recinto Sagrado, encima de un cerro que domina el sitio entero. Se compone de una media docena de plataformas escalonadas de adobes con escaleras internas conectando los varios niveles. En la cumbre -hoy un espacio plano con pocos vestigios- se encontraban dos construcciones principales: un Punchao Cancha con una ventana frente al valle y otro santuario probablemente dedicado al mismo Pachacámac, frente al Océano Pacífico (Eeckhout 1998a). El estudio de Viracocha y el Sol (Inti) llevado a cabo por Demarest (1981:23-30) muestra el carácter múltiple de los dioses del panteón superior Inka. Dicho autor desarrolla de manera convincente la idea de una "tríada solar" que se puede resumir de la manera siguiente:

- Apu-Inti, "Sol Verdadero", "Sol Adulto", un Criador asimilado a Viracocha;

- Churi-Inti, "Sol Joven", considerado como "Punchao" (el Día);

- Inti-Guauqui, "Sol como donador de vida", patrón de los Inkas y centro del culto estatal a los ancestros.

Una cita de Avila nos informa respecto a las relaciones entre Inti y Pachacámac:

"Se dice que cuando los ingas estaban en las tierras altas, celebraban el culto del sol al que adoraban en su santuario de Titicaca diciendo:

Es éste quien nos ha animado a nosostros los ingas" (...) los ingas creían que los límites de la tierra se encontraban en Titicaca y, por la otra parte del mar, en las tierras de Pachacamac; más allá no había más nada. Era quizá a causa de esta creencia que adoraban a estos dos huacas más que a todas las demás y levantaron una imagen del sol en las proximidades de Pachacámac de Abajo. Y hasta hoy se llama ese lugar Punchaucancha (Avila 1987:cap. XXII).

Pachacámac pues sería el Criador hurin, de abajo, y Viracocha (asimilado al sol), el hanan de arriba $^{1}$. El análisis puede ser llevado un poco más lejos. En efecto, por lo que concierne a las fiestas rituales celebradas por los Inkas en honor al Sol, Demarest (1981:26-7) demuestra que Apu-Inti ("Sol Adulto", Viracocha) fue el patrón del Capac Raymi, la fiesta del solsticio de verano (noviembre), cuando el sol es alto y fuerte. Churi-Inti ("Sol Joven") es el patrón del Inti Raymi, la fiesta del solsticio de invierno (junio), cuando el Sol se en- 
cuentra en su posición más baja y norteña: es entonces considerado como débil y joven (Figura 1). Churi-Inti no tiene aspecto de criador para los Inkas, es asimilado al Punchao, el Día, y es precisamente un Punchao Cancha (Templo del Día) que se construyó en Pachacámac, ubicado al noroeste del Cuzco, es decir, la dirección donde está el Sol Joven en junio en las tierras altas.

A mi modo de ver, los Inkas así manifiestan que reconocen a Ychsma-Pachacámac como el criador de los llanos (mientras Viracocha es ApuInti, el criador serrano), pero, por otro lado, incluyen el sitio en su paisaje mítico pues lo hacen el lugar donde se venera el Sol Joven, Sol del Día, el Punchao. En cuanto a Ychsma, vale la pena recordar su asociación recurrente con la Luna en los relatos míticos, la iconografía y las prácticas rituales (Krickeberg 1971:167-81, 245-8; Rostworowski 1991; Eeckhout 1993, 1998b). Efectivamente, la conquista inka de Ychsma y la construcción de un Templo del Día dominando al sitio entero aparece como una victoria doble: los serranos frente a los costeños, y el Criador Solar frente al Criador Lunar. Más que un logro diplomático o militar, es un acto de naturaleza profundamente religiosa el que se cumple. Desde el pun- to de vista simbólico y cosmológico, los Inkas aseguran de esta manera su dominio sobre el universo entero.

El Templo se consideraba uno de los más importantes del Imperio, al igual que los de la isla del Sol del Titicaca y del Coricancha en Cuzco. La misma clase de restricciones de acceso se aplicaba en esos santuarios: ayuno ritual, etapas sucesivas y acercamiento progresivo por patios restringidos (Bauer y Stanish 2001:213-40; Hyslop 1990:45; Pizarro 1872). Tanto en Pachacámac como en el Santuario del Titicaca, sólo unos individuos con estatus especial estuvieron autorizados a tener un contacto directo con el Idolo o la Roca Sagrada. Así como Bauer y Stanish (2001:244-9) lo mostraron, ese control estrecho de los cultos más solemnes formaba parte integral de las estrategias sociopolíticas Inkas de dominación.

La necesidad imperial de paz y unificación interétnica justificó la organización de romerías a gran escala, y desde lugares lejanos hacia esos sitios. Ese cambio en las peregrinaciones desde el nivel local hacia el interregional se nota en Pachacámac por el incremento espectacular de las instalaciones de peregrinaje. Durante el período Intermedio Tardío los peregrinos se juntaban proba-

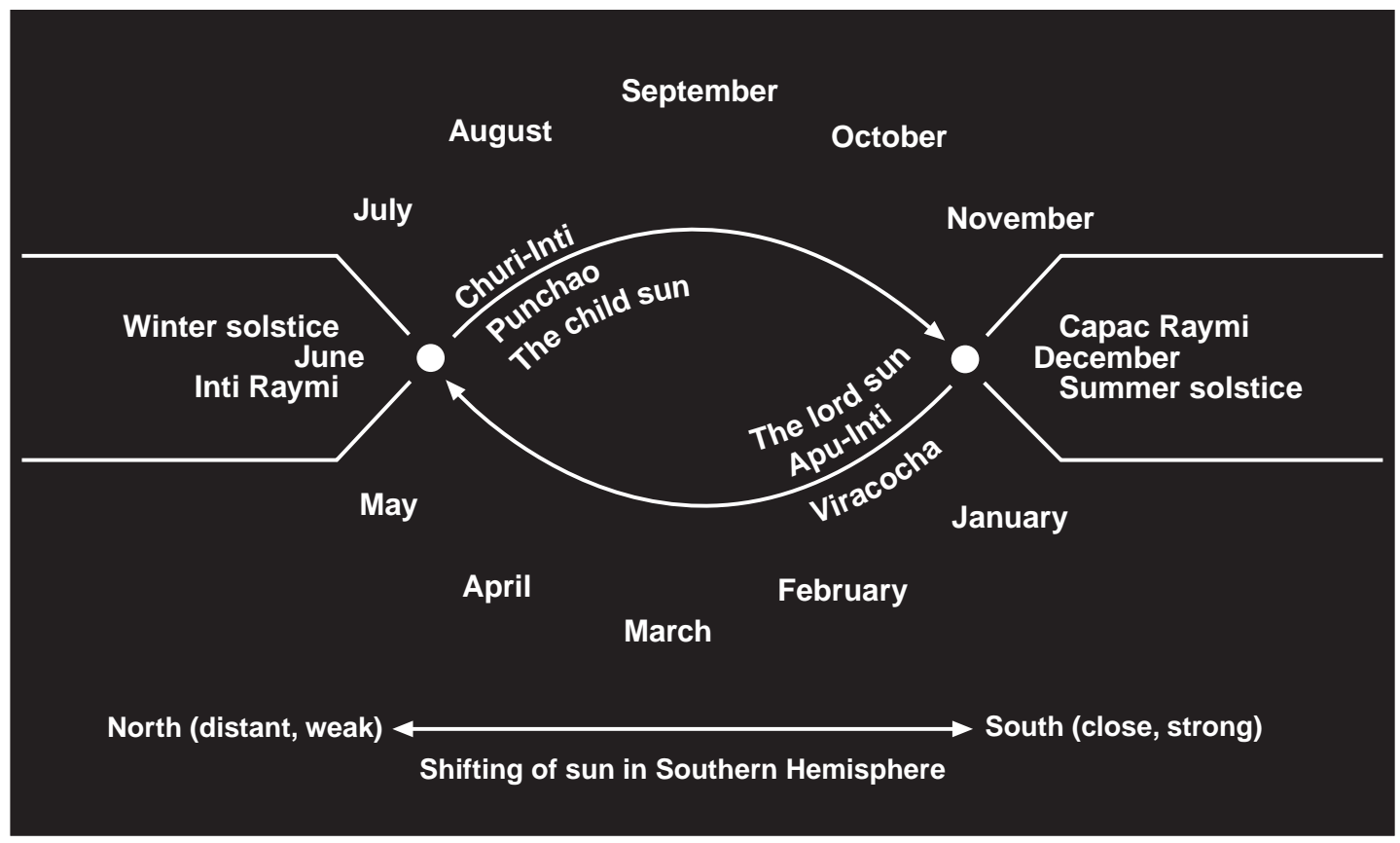

Figura 1. División solsticial de la tríada solar (de Demarest 1981, Figura 4).

Solsticial division of the solar triad (after Demarest 1981, Figure 4). 
blemente en la Sala ${ }^{\circ}$ 26, al final de la calle Norte-Sur que atraviesa el sitio (Figura 2). Durante el Horizonte Tardío, los Inkas construyeron la Plaza de los Peregrinos, un complejo de patios de 5 hectáreas con columnas, donde los peregrinos tenían que esperar un año entero antes de ingresar en el Recinto Sagrado y consultar al Oráculo. La plaza de los Peregrinos es 20 veces más grande que la Sala ${ }^{\circ} 26$.

En la parte oriental del muro separando la Plaza de los Peregrinos del Recinto Sagrado se encuentra un gran ushnu, que ha sido excavado y restaurado hace poco (Figura 3). Según Hyslop, el uso ritual primario del ushnu toma un papel más público en las provincias conquistadas, pues

\section{the platform fulfilled a political function} where Inka and governers came together with local leaders, and where troops were reviewed. The Inka solar religion was closely tied to the ushnu (Hyslop 1990:101).
En Pachacámac, el ushnu también constituye la entrada obligatoria hacia el Recinto Sagrado, el lugar donde los oficiales del culto recibían las ofrendas de los peregrinos, y adonde llegaba el tributo que se almacenaba en los depósitos del Templo del Sol. Por eso le llama Uhle "The Porter's Lodge". La ubicación del ushnu en Pachacámac ilustra perfectamente la ideología del imperialismo Inka, caracterizado por una combinación de motivaciones políticas, económicas y religiosas.

El Acllahuasi es una de las escasas construcciones Inka en la costa que tiene mampostería elaborada de piedra labrada. Resulta difícil asegurar cuál fue el aspecto original del edificio, por las restauraciones de Tello. Sin embargo, es uno de los edificios más amplios de su clase, y según las estimaciones de Uhle (1903:101), albergaba a unas 200 mujeres escogidas. Al igual que en las otras estructuras del mismo tipo en el Imperio, las $a c$ llas de Pachacámac representaban una fuente importante de recursos económicos, pues proporcio-

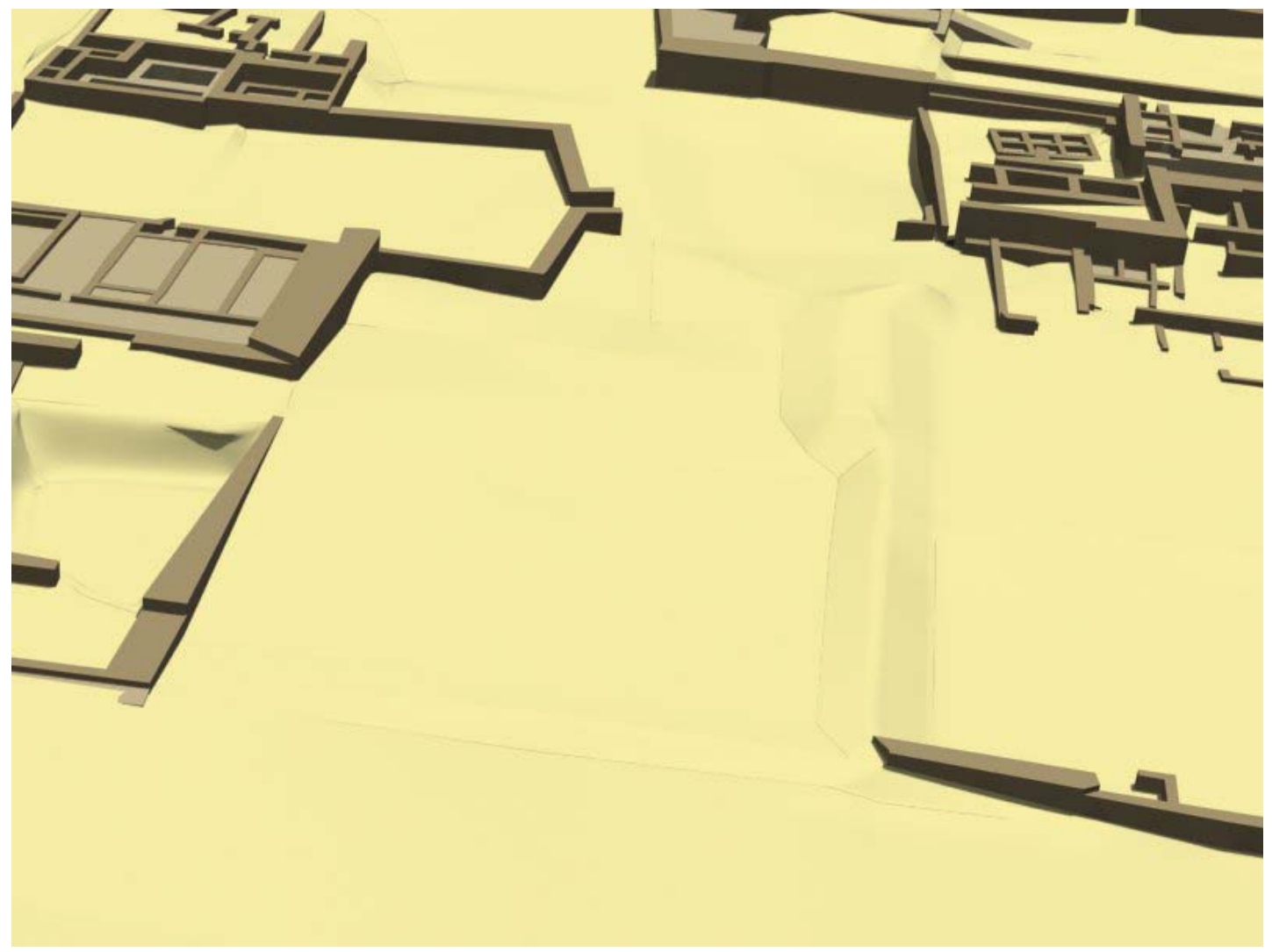

Figura 2. Reconstitución virtual de la sala 26 en Pachacámac, vista desde el sur. Virtual reconstitution of room 26 at Pachacamac, view from the south. 


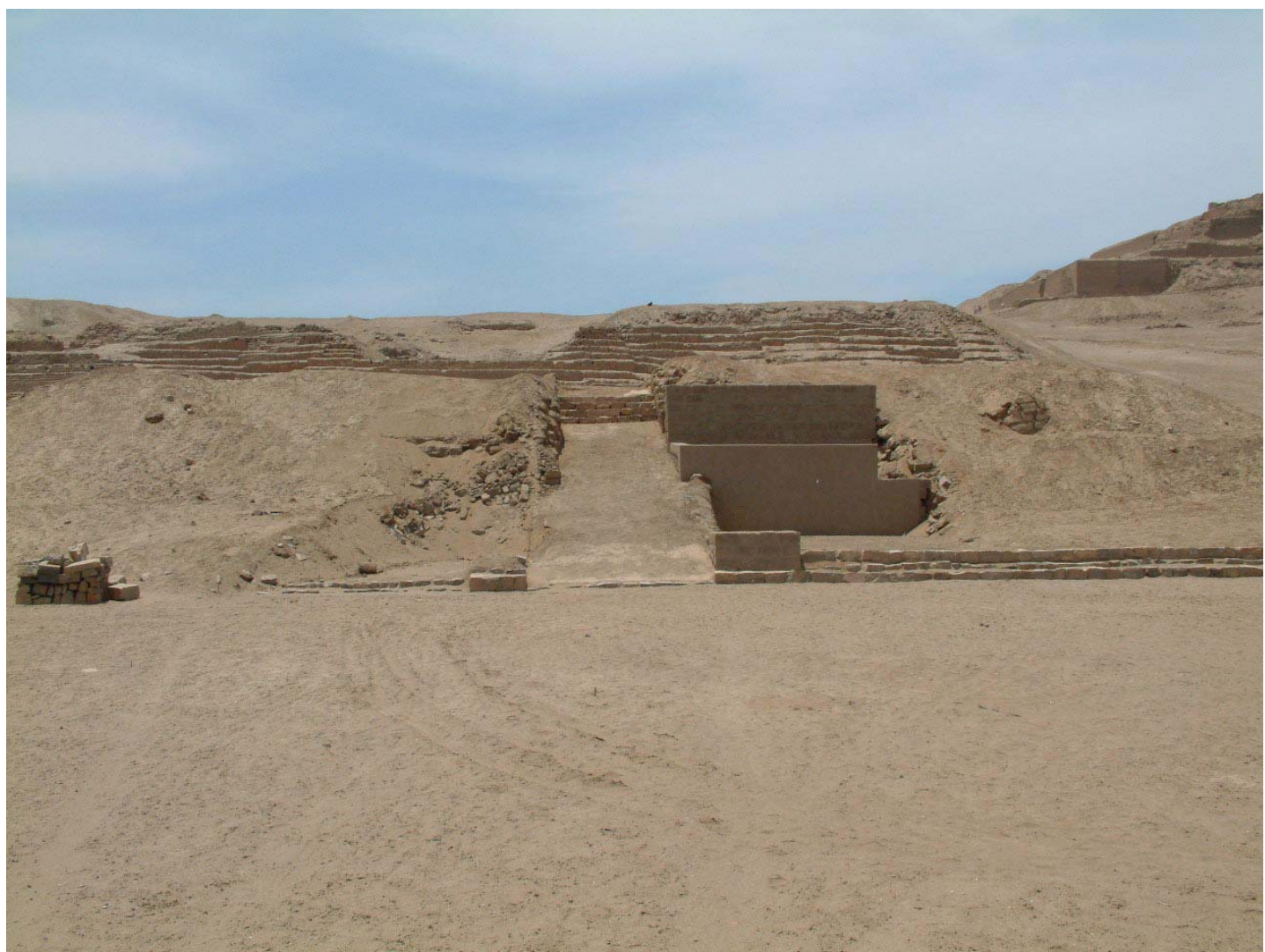

Figura 3. Ushnu de Pachacámac restaurado, visto desde el oeste. Restored Ushnu of Pachacamac, view from the west.

naban textiles finos de cumbi para el estado. En términos políticos, su utilidad fue consistente, pues algunas eran regaladas por el Inka como esposas a sus aliados así como a los curacas que se sometían a su autoridad (Rowe 1946). Las evidencias etnohistóricas sugieren que las acllas criaban peces sagrados en los estanques frente al Acllahuasi. El pescado lo llevaban los chaskis al Cuzco porque su consumo fue un privilegio reservado al mismo Sapa Inka (Espinoza Soriano 1974). Otra vez, la economía, la política y la religión se juntan en una institución dedicada a los objetivos del Imperio ${ }^{2}$.

Los Inkas hicieron sentir su presencia en todo el valle de Lurín, donde llevaron cambios sustanciales en la arquitectura y los asentamientos. Por ejemplo, Jane Feltham (1983) ha mostrado de qué manera sus nuevas ideas influenciaron la arquitectura de élite en el valle.

Por otro lado, la manera en la cual los elementos arquitectónicos tradicionales de la élite -como las rampas centrales y las plataformas con conjun- to de recintos en U- se usaron durante el Horizonte Tardío refleja las transformaciones de las jerarquías políticas locales llevadas a cabo por los Inkas. En Pachacámac, donde los curacas principales perdieron el poder, el diseño general de las estructuras se preservó, pero los antiguos elementos se cubrieron, como en el llamado "Palacio de Tauri Chumpi", la supuesta residencia del Tucrikuk Inka. Dicho edificio se construyó encima de una antigua pirámide con rampa, las sedes tradicionales de poder en la región. Las obras llevadas a cabo por Alberto Bueno sacaron a la luz la antigua rampa central, parcialmente cortada y luego recubierta por una plataforma (Figura 4). Hay que agregar que el plano de la antigua pirámide sirvió de esquema conductor para la estructura del Horizonte Tardío ${ }^{3}$.

Excavaciones recientes sugieren que otras estructuras similares se arrasaron para la construcción de la Plaza de los Peregrinos (Ramos Giraldo comunicación personal 2000). Ninguna pirámide funcionó bajo el dominio inka: se abandonaron, se 


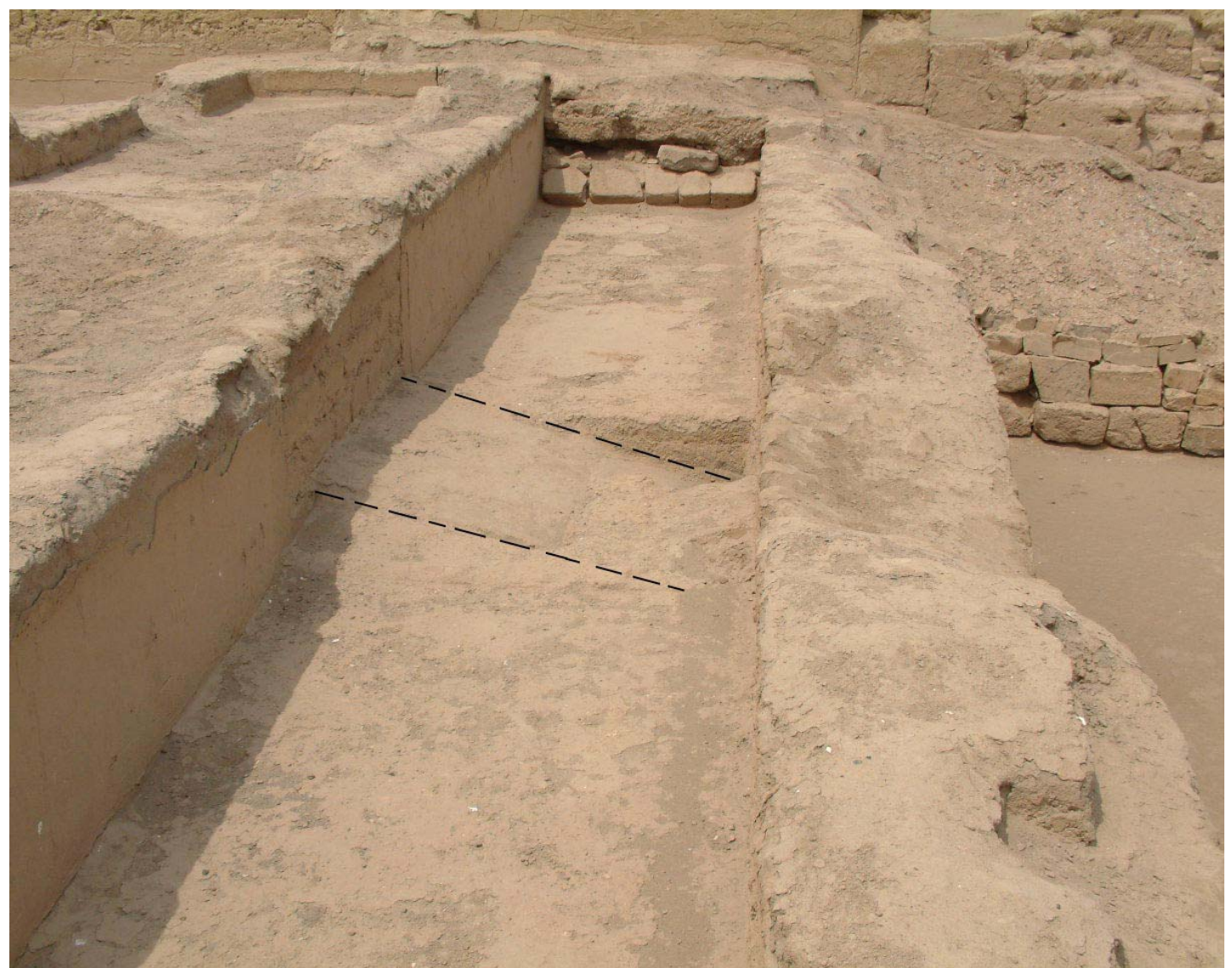

Figura 4: Palacio de Tauri Chumpi en Pachacámac, detalle de la antigua rampa cubierta por remodelaciones en la época Inka. Tauri Chumpi palace at Pachacámac, detail of the ancient ramp covered by an Inka remodeling.

usaron como cementerios y campamentos para los peregrinos. Por otro lado, en el valle, los mismos elementos típicos de la élite se integraron en edificios administrativos inkas, por ejemplo la rampa central y su plataforma asociada en el Conjunto de las Ventanas en Huaycán. En otros casos, las antiguas pirámides siguieron siendo usadas y fueron hasta ampliadas mediante añadidos tardíos, como los muros y recintos adicionales en adobones de estilo Inka en Pampa de las Flores, valle bajo de Lurín. Este hecho sostiene la idea de que las autoridades locales secundarias conservaron y tal vez extendieron su poder, bajo el control estricto de los Inkas.

Estos ejemplos son indicativos de la integración completa de los establecimientos del Lurín en el molde imperial. Hay otras indicaciones, por ejemplo en el registro alfarero y textil, pero los estudios no están completos todavía.

\section{Discusión}

De todo lo que se ha descrito y explicado arriba, sobresalen varias características que proporcionan interesantes sugerencias en cuanto a la manera en la cual los Inkas manejaron y manipularon los elementos específicos de la identidad local Ychsma.

Primero, a nivel religioso, los Inkas imponen de manera muy sutil su propio culto y respetan de alguna manera las creencias locales, que ciertamente compartían, sea parcialmente. Los comentarios de Garcilaso referentes a las negociaciones entre el curaca principal del sitio y Topa Yupanqui son muy elocuentes al respecto, pues se concluye la paz sin haber intercambio de un solo golpe, y en las condiciones siguientes:

que adorasen los yuncas al sol, como los Incas; que le hiciesen templo aparte 
como al Pachacámac, donde le sacrificasen y ofreciesen sus dones, con que no fuesen de sangre humana (porque era contra ley natural matar un hombre a otro para ofrecerlo en sacrificio, lo cual se quitase totalmente). Que echasen los ídolos que había en el templo de Pachacámac (...) que se fundase en el valle Pachacámac casa de las vírgenes escogidas (...); que el rey Cuismancu se quedase en su señorío (como todos los demás curacas) teniendo el Inca por supremo señor (...) (Garcilaso 1991, Lib. 6, cap. XXXI:396).

Sabemos que los referidos ídolos -"la zorra y otros animales del mar" (Garcilaso 1991:395)tenían sin embargo un papel durante ceremonias inkas tan importante como el Inti Raymi, cuando se intercambiaban ofrendas. El Inka daba a los curacas de las varias provincias copas de oro que usaba para alimentar al sol mientras dichos curacas le regalaban al Inka “(...) sus vasos y otras cosas de oro y plata que para presentar al sol habían traído de sus tierras: como ovejas, corderos, lagartijas, sapos, culebras, zorras, tigres y leones y mucha variedad de aves. En fin, de lo que más abundancia había en sus provincias (...) (Garcilaso 1991, Lib. 6, cap. XXI:372-73). El simbolismo es obvio: el sol de los Inkas a cambio de los animales sagrados particulares de cada provincia sometida. Además, las descripciones de Cieza de León (1995, Parte 1, cap. LXXII:213) y Cobo (1964:187) nos informan sobre la presencia en el Templo del Sol de pinturas murales con representaciones de animales, lo que sugiere que la modificación imperial del culto fue más formal que real. En cuanto a los sacrificios humanos, es obvio que esa práctica no se termina con la integración del sitio al Imperio, sino que probablemente se vuelve un privilegio Inka, así como lo atestiguan los hallazgos de Uhle (1903:84-88) en el mismo Templo del Sol, y los que se excavaron en Pampa de Flores (Eeckhout 1999b).

La organización del peregrinaje a gran escala se inspira en el mismo principio que la del culto, es decir, que por un lado se le da a esa práctica (con toda probabilidad ya existente desde generaciones) una importancia que nunca había logrado tener, mientras por otro lado es controlada y usada en beneficio del estado.
Segundo, a nivel político, los Inkas usan de los símbolos locales de poder secular para asentar su propio poder, tal como es el caso para la arquitectura tradicional de élite-las pirámides con rampa- cuyo diseño inspira los palacios de gobernadores imperiales en el Horizonte Tardío. Este modo de actuación permite tanto a las poblaciones locales preservar sus referencias ideológicas y los símbolos que las encarnan, como a los Inkas de integrar esa ideología y simbología del poder en su provecho. El mismo proceso aparece claramente en el diseño del Templo del Sol cuya forma general escalonada imita a los templos locales, mientras las partes superiores constan de elementos típicamente Inkas. En los sitios secundarios del valle, permanecen los señores locales, y algunos hasta usan elementos arquitectónicos "importados" para manifestar su fidelidad a los nuevos señores.

El éxito de los Inkas pues descansa, en ese caso, sobre un conocimiento bastante profundo de la identidad y de la especificidad cultural del pueblo y de la comarca que conquistaron. El manejo muy hábil de una serie de elementos seleccionados permitió una integración "suave" de los Ychsmas en el Imperio. A un nivel más general, el conocimiento y el respeto de la identidad del "vencido" aparece como un factor importante para el beneficio del mismo vencedor: durante las 2 ó 3 generaciones de dominio del Tahuantinsuyu en Pachacámac, el sitio prosperó como no lo había hecho hasta entonces, mientras en el mismo espacio de tiempo tras de la conquista española, fue totalmente abandonado y la demografía de la comarca bajó un $90 \%$ (Rostworowski 1992:118-120). Eso significó por supuesto menos mano de obra, menos impuestos, y al final, menos recursos para el poder establecido. Por más que parte de esta dramática disminución de la población se debe a factores biológicos incontrolables, las modificaciones profundas llevadas a cabo por la administración colonial en los mecanismos y estructuras sociales locales, que constituyen parte de la identidad autóctona, han tenido un impacto contraproducente que nadie hoy puede negar...

Agradecimientos. Quisiera agradecer especialmente a María Jesús Jiménez Díaz por haber revisado la traducción del presente ensayo. Asumo la total responsabilidad del contenido, así como de los errores que pudieran quedar. 


\section{Referencias Citadas}

Avila, F. de

1987 [1608?] Ritos et Tradiciones de Huarochiri del Siglo $X V I I$. Versión paleográfica, interpretación fonológica y traducción al castellano por Gérald Taylor. Instituto de Estudios Peruanos e Instituto Francés de Estudios Andinos, Lima.

Bauer, B.S. y C. Stanish

2001 Ritual and Pilgrimage in the Ancient Andes. The Islands of the Sun and the Moon. University of Texas Press, Austin.

Brundage, B.C.

1963 Empire of the Inca. University of Oklahoma Press, Norman.

Cieza de León, P.

1995 [1551] La Crónica del Perú. Pontificia Universidad Católica del Perú, Lima.

Cobo, Fr. B.

1956 [1653] Historia del Nuevo Mundo. Biblioteca de Autores Españoles, T. 41-42. Ediciones Atlas, Madrid.

Conrad, G.W. y A.A. Demarest

1984 Religion and Empire. Cambridge University Press, Cambridge.

D'Altroy, T.

1992 Provincial Power in the Inka Empire. Smithsonian Institution Press, Washington and London.

Demarest, A.A.

1981 Viracocha. The Nature and Antiquity of the Andean High God. Peabody Museum Monographs, 6. Harvard University, Cambridge.

Eeckhout, P.

1993 Le Créateur et le Devin. A propos de Pachacamac, dieu précolombien de la Côte Centrale du Pérou. Revista Española de Antropología Americana 23:135-52.

1998a Le temple de Pachacamac sous l'Empire inka. Journal de la Société des Américanistes 84:9-44.

1998 be renard Yunga. Une figure symbolique préhispanique. Revista Española de Antropología Americana 28:119-49.

1999a Pirámide con rampa n III, Pachacámac. Nuevos datos, nuevas perspectivas. Boletín del Instituto Francés de Estudios Andinos 28(2):169-214.

1999b Les sacrifiés de Pampa de las Florès. Contribution archéologique à l'étude du sacrifice humain dans les Andes préhispaniques. Recherches Amérindiennes au Québec 29:18-50.

2003 Ancient Monuments and Patterns of Power at Pachacamac, Central Coast of Peru. Beiträge zur Allgemeine und Vergleichenden Archäologie 23:139-182.

Espinoza Soriano, W.

1974 El Templo Solar de Paramonga y los Acuarios de Pachacámac. Bulletin de l'Institut Français d'Etudes Andines 3(3):1-22.

Feltham, J.P.

1983 The Lurin Valley, Peru: AD1000-1532. Ph.D. Dissertation Institute of Archaeology, University of London, Londres.

Garcilaso de la Vega, Inka

1991 [1609] Comentarios Reales de los Inkas (2 Vol.). Fondo de Cultura Económica, Lima.
Hyslop, J.

1990 Inka Settlement Planning. University of Texas Press, Austin.

Krickeberg, W.

1971 Mitos y Leyendas de los Aztecas, Incas, Mayas y Muiscas. Fondo de Cultura Económica, México.

Malpass, M.A., editor.

1994 Provincial Inka. Archaeological and Ethnohistorical Assessment of the Impact of the Inka State.University of Iowa Press, Iowa City.

Matos Mendieta, R.

1997 Incas y etnias regionales en Junín. Una visión arqueológica. En Arqueología, Antropología e Historia en los Andes. Homenaje a María Rostworowski, editado por R. Varón Gabai y J. Flores Espinoza, pp. 397-414. Instituto de Estudios Peruanos-Banco Central de Reserva del Perú, Lima.

Morris, C. y D.E. Thompson

1985 Huánuco Pampa: An Inka City and Its Hinterland. Thames and Hudson, London.

Pizarro, $\mathrm{H}$.

1872 [1533] A Letter of Hernando Pizarro to the Royal Audience of Santo Domingo, November 1533. En Reports on the Discovery of Peru, III, editado por C.R. Markham, pp. 111-127. Hayklut Society, Londres.

Rostworowski de Diez Canseco, M.

1991 Algunos Mitos Referentes al Dios Pachacámac. En El Umbral de los Dioses, editado por M. Lemlij y L. Millones, pp. 47-67. Biblioteca Peruana de Psicoanálisis, 6. SIDEA, Lima.

1992 Pachacámac y el Señor de los Milagros. Una Trayectoria Milenaria. Instituto de Estudios Peruanos, Lima.

Rowe, J.H.

1946 Inca Culture at the time of the Spanish Conquest. En Handbook of South American Indians (Vol. II), editado por J.H. Steward, pp. 183-330. Bureau of American Ethnology, Bulletin 143, Washington.

Santillán, H. de

1879 [1563] Relación del origen, descendencia, política y gobierno de los Incas. En Tres Relaciones de Antigüedades Peruanas, pp. 15-185. Ministerio del Fomento, Madrid.

Schreiber, K.J.

1992 Wari Imperialism in Middle Horizon Peru. Anthropological Papers 87. Museum of Anthropology, University of Michigan, Ann Arbor.

Spalding, K.

1984 Huarochiri. Andean Society Under Inca and Spanish Rule. Stanford University Press, Stanford.

Uhle, M.

1903 Pachacamac. Report of The William Pepper, M.D., LL.D. Peruvian Expedition of 1896.The Dpt of Archaeology of the University of Pennsylvania, Philadelphie.

Von Hagen, A. y C. Morris

1998 The Cities of the Ancient Andes. Thames and Hudson, London and New York. 


\section{Notas}

1 Esta idea se confirma por el nombre del río Lurín (= $h u$ rin), pues dicho río se llamaba originalmente Ychsma (Santillán 1879:32-33).

2 Sobre el tema de la religión como parte de la ideología imperial Inka, ver Conrad y Demarest (1984).
$3 \mathrm{Al}$ respecto, es interesante recordar que el plano de Tauri Chumpi es muy similar al del Sector III de Tambo Colorado, famoso sitio Inka del valle de Pisco. Eso sugiere que los Inkas no solamente se inspiraron en las pirámides de Pachacámac para sus estructuras de élite en el sitio, sino también desarrollaron y exportaron el modelo a otras zonas costeñas. 